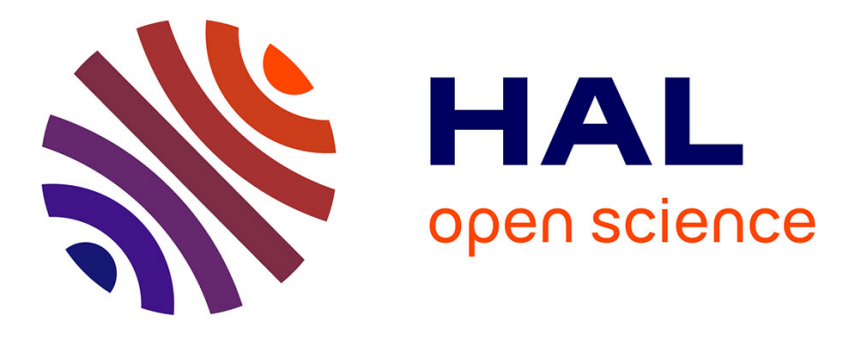

\title{
Laser-assisted machining of Inconel 718 with carbide and ceramic inserts
}

Guenael Germain, Jean-Lou Lebrun, Tarek Bouchnak Braham, Daniel Bellett, Stéphane Auger

\section{- To cite this version:}

Guenael Germain, Jean-Lou Lebrun, Tarek Bouchnak Braham, Daniel Bellett, Stéphane Auger. Laserassisted machining of Inconel 718 with carbide and ceramic inserts. International Journal of Material Forming, 2008, 1 (1), p. 523-526. 10.1007/s12289-008-0213-y . hal-00750868

\section{HAL Id: hal-00750868 https://hal.science/hal-00750868}

Submitted on 12 Nov 2012

HAL is a multi-disciplinary open access archive for the deposit and dissemination of scientific research documents, whether they are published or not. The documents may come from teaching and research institutions in France or abroad, or from public or private research centers.
L'archive ouverte pluridisciplinaire HAL, est destinée au dépôt et à la diffusion de documents scientifiques de niveau recherche, publiés ou non, émanant des établissements d'enseignement et de recherche français ou étrangers, des laboratoires publics ou privés. 


\title{
Laser-assisted machining of Inconel 718 with carbide and ceramic inserts
}

\author{
G. Germain ${ }^{1}$, J.L. Lebrun ${ }^{1}$, T. Braham-Bouchnak ${ }^{1}$, D. Bellett ${ }^{1}$, S. Auger ${ }^{2}$ \\ ${ }^{1}$ ENSAM CER d Angers, LPMI/EPPM-EA1427, 2 bd de Ronceray 49035 Angers, France \\ URL:www.ensam.eu e-mail: guenael.germain@angers.ensam.fr \\ ${ }^{2}$ CETIM site de Senlis, . 52 Avenue Félix-Louat 60304 Senlis, France \\ URL: www.cetim.fr \\ e-mail: stephane.auger@cetim.fr
}

ABSTRACT: Laser assisted machining (LAM) can improve the machinability of materials by locally heating the material prior to its removal. The work presented here is a study of the laser assisted machining of Inconel $718(\mathrm{NiCr} 19 \mathrm{FeNb}$ at $46 \mathrm{HRc})$ with carbide and ceramic insert. The tests have shown a reduction in the cutting force, and have highlighted the impact of laser assistance on the integrity surface (roughness, appearance, residual stress) and the tool life.

Key words: LAM, Inconel 718, superallows, machinability, tool life, tool wear, surface integrity

\section{PRESENTATION}

\subsection{Introduction}

The use of high strength materials, like titanium alloys and tool steels, is becoming increasingly common in industry. However, these materials are difficult to machine because they maintain their mechanical properties even at high temperatures. Hence, conventional machining (CM) of these materials is slow and inefficient because only slow cutting speeds can be used. In order to increase productivity certain types of assistance $\square$ can be used to facilitate the cut. It has already been shown that LAM makes it possible to machine high strength metals like bearing steel [1], Ti6Al4V [2, 3], boron [4], metal matrix composites [5] and ceramics [6-7]. For these materials, it improves workability by decreasing the cutting forces and by increasing the tool life. This process is currently the only process able to machine very hard materials.

\subsection{Principle of LAM}

LAM is a high temperature cutting process using a laser beam as the heat source (Figure 1). The principle of the process is to reduce the cutting force necessary to machine the material by increasing the temperature to the point where the strength of the material is reduced (Figure 2). Indeed at high temperature, the specific cutting energy is weak, which improves workability. Figure 2 shows the characteristic evolution of the ultimate tensile strength of various materials with regard to temperature [3].

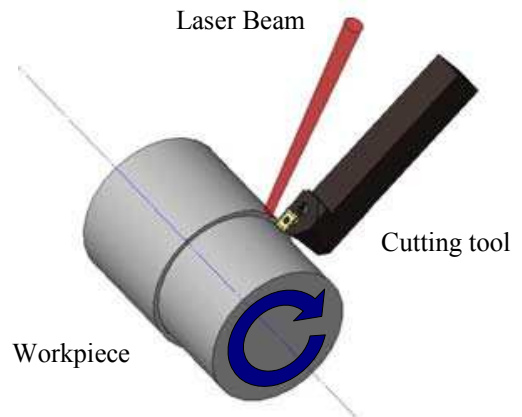

Fig. 1: LAM configuration (turning operation)

For most materials a drop in the tensile strength or hardness occurs near $500^{\circ} \mathrm{C}$. To be effective the cutting tool must thus operate in the zone where the temperature remains higher than this value.

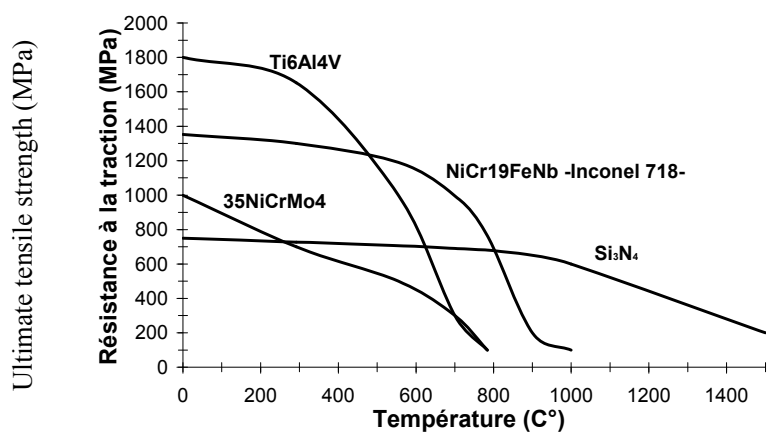

Fig. 2: Sensitivity of $\sigma_{\mathrm{UTS}}$ to the temperature for various materials [3]

The effect of the angle of incidence has been investigated by Germain et al [8-9]. In particular, it has been shown that the laser beam absorption is the same for all angles of incidence less than $40^{\circ}$ relative to the surface normal. For all the work reported in this article, the angle of incidence was set equal to $20^{\circ}$ relative to the surface normal in order to prevent the laser nozzle from hitting the tool. 


\subsection{Experimental equipment}

A numerically controlled lathe (REALMECA RT-5) equipped with a $2.5 \mathrm{~kW}$ ROFIN YAG laser was used in this work. The laser nozzle can be controlled using three translations and two rotations. A numerical control system (NUM 1060) allows the control of the seven independent degrees of freedom. The highpower laser beam is delivered through a fibre optic cable to the lathe chamber, where it is focused on the workpiece surface. During machining, a gas under pressure (air) is forced through the laser nozzle to protect the focusing lens from being damaged by chips. Three components of the cutting force are measured by a Kistler piezoelectric dynamometer.

\subsection{Material investigated}

The material under investigation is the nickel alloy $\mathrm{NiCr} 19 \mathrm{FeNb}$ which is known commercially as Inconel 718. It has been structurally hardened via a heat treatment consisting of quenching (from 940 to $\left.1010^{\circ} \mathrm{C}\right)$ and structural hardening $\left(720^{\circ} \mathrm{C}\right.$ for $8 \mathrm{hr}$ followed by $620^{\circ} \mathrm{C}$ for $8 \mathrm{~h}$ ). The microstructure is austenitic with a grain size index of $G=10$. The hardness of the material is uniform and has an average value of $482 \mathrm{HV}$ (46 HRc).

\subsection{Cutting parameters used with the carbide insert}

Tests were carried out with the cutting parameters recommended by the CETIM for this type of insert and with several laser Powers: 0 Watts (conventional machining), 1165 and 1975 Watts. The cutting parameters recommended are: Carbide tool insert KC5525 (Kennametal) ref. CNMG 120412 RP; advance, $\mathrm{f}=0.2 \mathrm{~mm} / \mathrm{rev}$; cutting depth, ap $=2.5$ $\mathrm{mm}$; cutting speed, $\mathrm{Vc}=30 \mathrm{~m} / \mathrm{min}$; without lubrication. Material removal rate of $15 \mathrm{~cm}^{3} \cdot \mathrm{min}^{-1}$. A new cutting edge was used for each test. The laser beam was focused on the chamfered cut surface approximately $5 \mathrm{~mm}$ from the cutting tool.

The three components of the cutting force, the surface integrity (roughness, residual stresses), and the tool life were measured for each test.

\subsection{Parameters used with the ceramic insert}

Similarly, the cutting parameters used for the ceramic insert are those recommended by the CETIM: CC670 ceramic insert (Sandvik) ref. RNGN 090300; advance, $\mathrm{f}=0.18 \mathrm{~mm} / \mathrm{rev}$; cutting depth, ap $=1.5 \mathrm{~mm}$; cutting speed, $\mathrm{Vc}=220 \mathrm{~m} / \mathrm{min}$; without lubrication. Material removal rate of $59.4 \mathrm{~cm}^{3} \cdot \mathrm{min}^{-1}$. The tests were carried out without laser assistance and with an assistance of 1500 Watts. The evolution of the tool wear, the three components of the cutting force, and the surface roughness, were measured for each test. The tool life and residual surface stresses were also determined.

\section{RESULTS OBTAINED WITH THE CARBIDE INSERT}

\subsection{Cutting force (carbide insert)}

The results show a decrease magnitude of the cutting force with the laser power (Figure.3). Specifically, there is a decrease of $6.5 \%$ with a laser power of $1165 \mathrm{~W}$ and $10.8 \%$ with a power of $1975 \mathrm{~W}$.

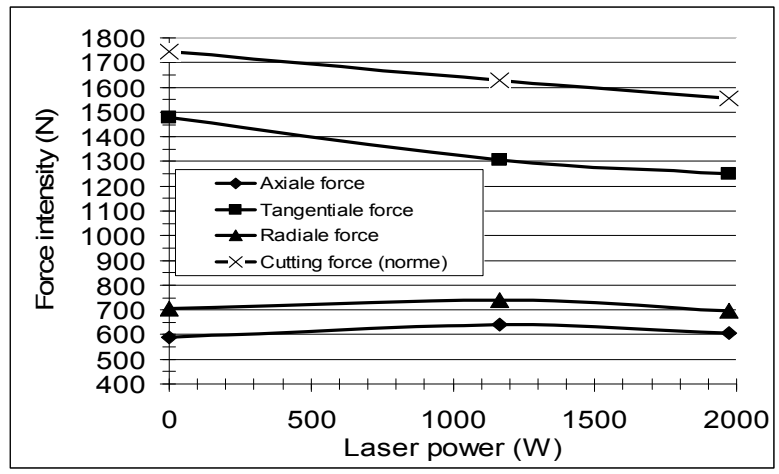

Fig 3: Evolution of the three components and the magnitude of the cutting force as a function of the laser power

\subsection{Surface Integrity (carbide insert)}

The impact of laser assistance on the surface integrity has been quantified by the evolution of several roughness criteria and the residual stresses on the cut surface. The three surface roughness criteria used are: the arithmetic average (Ra), the maximum height peak/valley (Rmax) and the average height peak/valley (Rz). The following figure (Figure 4) shows that laser assistance can influence the surface roughness of the workpiece. A high laser power results in a slight improvement of the roughness criteria.

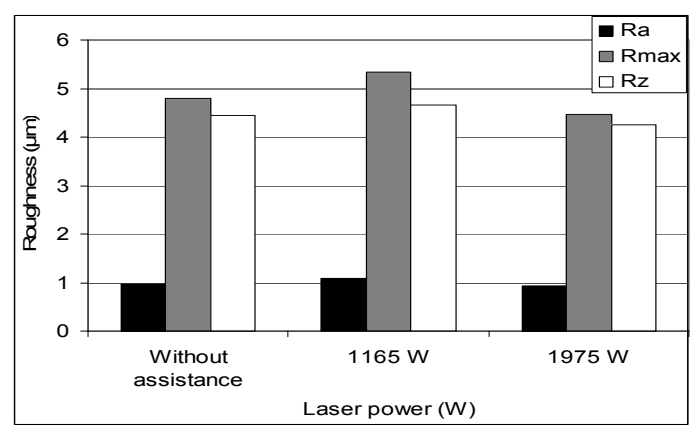

Fig 4: Evolution of the surface roughness as a function of laser power

The residual stresses were determined by X-ray diffraction. The analysis was carried out for the test without assistance (conventional machining - CM), 
and with the maximum laser power. The values obtained are summarised in the following table (Table1).

Table 1. Residual Stresses values on the cut surface

\begin{tabular}{|c|c|c|}
\hline Stress $(\mathrm{MPa})$ & $\mathrm{CM}$ & $\begin{array}{c}\text { LAM } \\
1975 \mathrm{~W}\end{array}$ \\
\hline Axial direction & $\mathbf{7 4 0} \pm \mathbf{2 5}$ & $\mathbf{5 2 0} \pm \mathbf{3 0}$ \\
\hline Tangential direction & $\mathbf{4 3 5} \pm \mathbf{4 5}$ & $\mathbf{4 4 0} \pm \mathbf{4 5}$ \\
\hline
\end{tabular}

The table shows that the residual stresses on the surface are positive (tensile stresses) for the two tests. The laser assistance decreases the residual stress in the axial direction.

\subsection{Tool wear (carbide insert)}

These initial results demonstrate an improvement in the machinability of Inconel 718 with laser assistance. However, the improvement is modest and there is a significant drop in tool life with the use of laser assistance. Indeed, the tool life is only $50 \mathrm{sec}$ with the laser assistance, compared to approximately $2 \mathrm{~min} 50 \mathrm{sec}$ in conventional machining. In both cases, the insert deteriorates very quickly with an almost instant failure of the cutting edge.

\section{RESULTS OBTAINED WITH THE CERAMIC INSERT}

\subsection{Cutting force (ceramic insert)}

The figure below (Figure 5) shows the evolution of the magnitude of the cutting force as a function of the distance machined for both conventional machining and LAM (1500 Watts). The cutting force in LAM is lower than in CM. Depending on tool wear, the reduction in the cutting force in UAL is between $40 \%$ and $20 \%$.

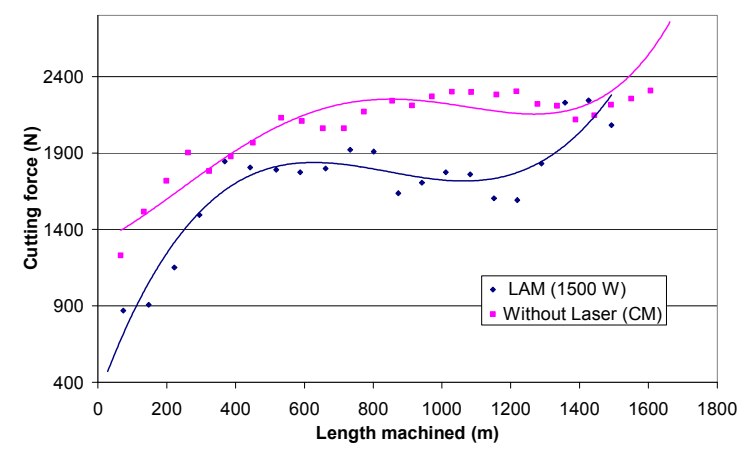

Fig 5: Evolution of the magnitude of the cutting force, in CM and in LAM, as a function of the distance machined

Inserts have machined respectively $1500 \mathrm{~m}$ in LAM and $1650 \mathrm{~m}$ in conventional machining prior to the collapse of the cutting edge. The beginning of the deteriorated area appears more rapidly in LAM $(1200 \mathrm{~m})$ than CM $(1400 \mathrm{~m})$. This deterioration results in an increase of the radial and axial components of the cutting force, but not the tangential component.

\subsection{Surface Integrity (ceramic insert)}

The surface integrity was quantified by the measurement of surface roughness (three criteria: $\mathrm{Ra}, \mathrm{Rmax}$ and $\mathrm{Rz}$ ), by the determination of surface residual stresses and by examination of the cut surface with a scanning electron microscope (SEM). The three roughness criteria show the same trend. Consequently only the $\mathrm{Ra}$ criterion is presented in figure 6 .

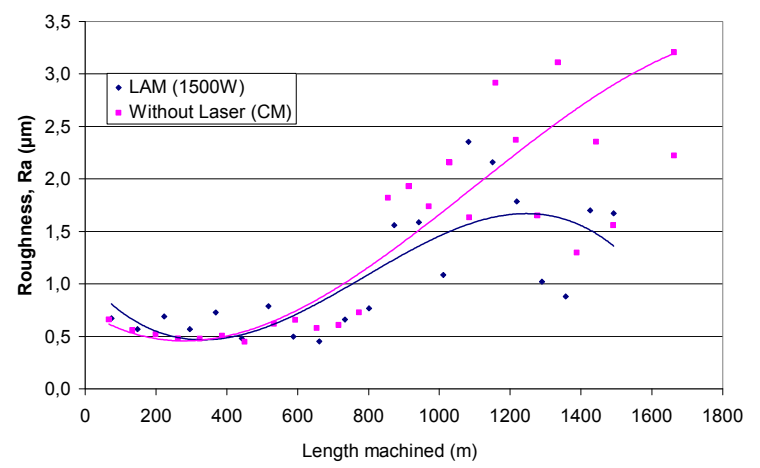

Fig 6: Evolution of the surface roughness (Ra), in CM and LAM, as a function of the distance machined

It can be seen that the evolutions of $\mathrm{Ra}$, in $\mathrm{CM}$ and LAM, are similar up to a machined distance of approximately $800 \mathrm{~m}$. After this distance, the roughness is lower and less dispersed for LAM. For conventional machining after approximately $800 \mathrm{~m}$, the roughness increase significantly and the data is widely scattered (scratches due to chips).

The analysis of residual stress was performed using a PROTO X-ray diffraction machine. The following table (Table 2) summarises the values of residual stress at the surface for the two types of machining.

Table 2: Surface residual stresses

\begin{tabular}{|c|c|c|}
\hline Stress $(\mathrm{MPa})$ & $\mathrm{CM}$ & $\begin{array}{c}\text { LAM } \\
1500 \mathrm{~W}\end{array}$ \\
\hline Axial direction & $\mathbf{1 6 0} \pm \mathbf{3 5}$ & $\mathbf{2 6 0} \pm \mathbf{3 5}$ \\
\hline Tangential direction & $\mathbf{2 7 0} \pm \mathbf{3 0}$ & $\mathbf{5 5 5} \pm \mathbf{4 5}$ \\
\hline
\end{tabular}

These values indicate that these cutting parameters result in positive or tensile residual stresses in both directions. In addition, LAM generates higher stresses due to thermal effects of laser heating. These values confirm the results obtained in other materials [9] and those found during the tests with carbide inserts.

The machined surfaces were observed with a scanning electron microscope. The figure 7 below shows pictures of the machined surfaces in CM (a) 
and LAM (b).

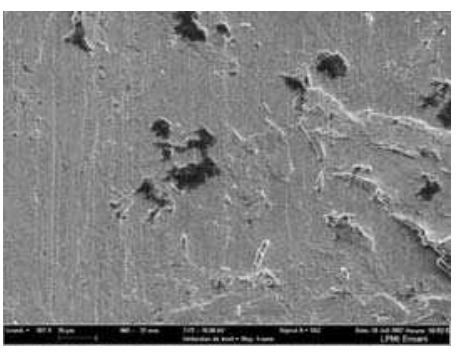

(a)

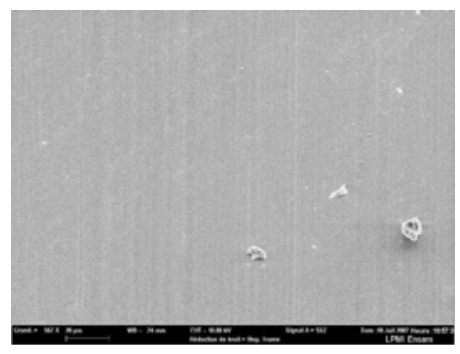

(b)
Fig 7: SEM photos of the machined surfaces in (a) CM and (b) LAM.

These photos (taken at the same magnification) demonstrate that the surface quality is considerably higher in LAM than in CM. In CM, the surface appears to be torn and dark spots, evenly distributed over the machined area, can be observed. Electron Diffusion Spectrometer (EDS) analyses were conducted to determine the nature of these dark spots. The EDS analyses show that all of the dark spots are caused by pollution of the surface by the tool insert. The presence of these elements (silicon, nitrogen, oxygen and aluminium) corresponds to a material deposit from the tool insert. This phenomenon is only visible on the conventional machined specimens. The machined parts in LAM demonstrate no such pollution.

\subsection{Tool wear (ceramic insert)}

The evolution of the wear on the clearance face, $\mathrm{Vb}$, is shown in figure 8 , for the two types of machining, as a function of the machined distance. The evolution of the clearance wear is different for machining with and without laser assistance. In conventional machining clearance wear increases approximately linearly, while for LAM three areas of change are visible.

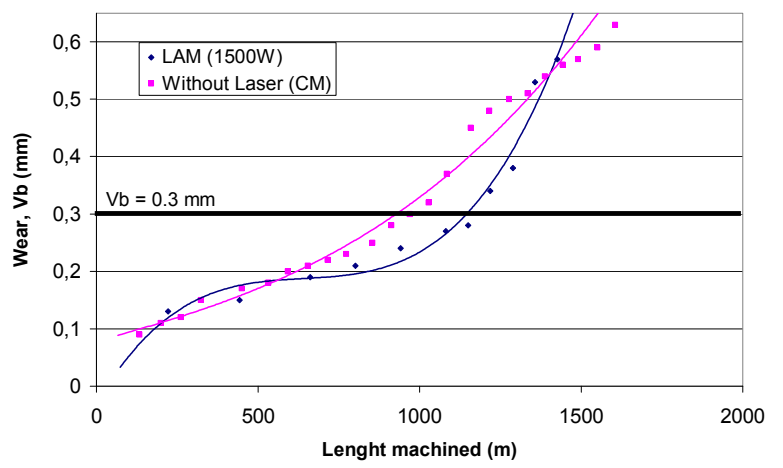

Fig 8: Evolution of wear $(\mathrm{Vb})$ as a function of the machined distance

In LAM, at the beginning of machining, up to about $400 \mathrm{~m}$, the wear increases rapidly (run-in). Then between about 400 and $1000 \mathrm{~m}$, the wear is relatively stable in LAM. By contrast, from $1000 \mathrm{~m}$ the degradation of the tool is greater in LAM with a very rapid increase in clearance wear.
For a maximum wear criterion set at $\mathrm{Vb}=0.3 \mathrm{~mm}$ (ISO standard), the tool life is $4 \mathrm{~min} 25 \mathrm{sec}$ in $\mathrm{CM}$ and $5 \mathrm{~min} 40 \mathrm{sec}$ in LAM.

\section{CONCLUSIONS}

This study, on the laser assisted machining of Inconel 718 has highlighted significant differences between the use of carbide inserts and ceramic inserts. In addition, comparisons with conventional machining were also conducted. Tests have shown that, no matter which insert is used, LAM significantly reduces the cutting force (up to $40 \%$ ). The integrity of the machined surface, in terms of roughness, is not improved with the use of ceramic inserts in LAM compared to CM. However, this gain is not visible with carbide inserts. Ceramic inserts allow a very good performance during the laser assisted machining, unlike carbide inserts. In fact, the life of a carbide insert in LAM is considerably lower than its life in CM, whereas the life of ceramic inserts in LAM increase by $25 \%$ compared to the life in CM.

\section{REFERENCES}

[1] Kainth G.S., Dey B.K., Experimental investigation into tool life and temperature during hot machining of EN-24 steels, Bulletin Cercle Etudes des Métaux 14 n¹1 (1980) p22.1-22.7

[2] Kitagawa T., Katsuhiro K., Kudo A., Plasma hot machining for high hardness metals, Bulletin Japon Society of Precision Engineering Vol.22 n² (1988) p145-151

[3] Lesourd B., Etude et modélisation des mécanismes de formation de bandes de cisaillement intense en coupe des métaux. Application au tournage assisté laser de 1alliage de titane TA6V, Thèse Ecole Centrale de Nantes (1996)

[4] Malot T., Usinage assisté par laser du bore, Thèse Université de Bourgogne (2001)

[5] Wang Y., Yang L.J., Wang N.J., An investigation of laserassisted machining of $\mathrm{Al}_{2} \mathrm{O}_{3}$ particule reinforced aluminium matrix composite, Materials Processing Technologies 129 (2002) p268-272

[6] Rebro P.A., Shin Y.C., Incropera F.P, Design of operating conditions for crackfree laser-assisted machining of mullite ceramic, International Journal of Machine Tools \& Manufacture 44 (2004) p667-694.

[7] Melhaoui A., Contribution à 1Cetude de 1 usure d outil de coupe en usinage asssité par laser et à 1 usinabilité dune céramique à base d oxyde de zinc, Thèse de 1ECP (1997)

[8] Germain G., Lebrun J-L., Robert P., Dal Santo P., Poitou A., Experimental and numerical approaches of Laser assisted turning, IJFP Vol. 8 - Special Issue 2005, Multiscale Simulations and Experiments to optimize Material Forming Processes (2005) p347-361

[9] Germain G., Morel F., Lebrun J-L., Morel A., Huneau B., Effect of laser assistance machining on residual stress and fatigue strength for a bearing steel $(100 \mathrm{Cr} 6)$ and a titanium alloy (Ti 6Al 4V), Materials Science Forum 524-525, (2006) p559-574 